\title{
Esterification of oleic acid employing sulfonated polystyrene and polysulfone membranes as catalysts
}

\author{
Ana Paula de Lima1 (D), Andressa Tirone Vieira2 ${ }^{(1)}$, Bárbara Nascimento Aud ${ }^{1,3}$ (D), \\ Antonio Carlos Ferreira Batista ${ }^{2}$ (D), Luís Carlos de Morais ${ }^{4}$ (D), Anízio Márcio de Faria ${ }^{2}$ (D), \\ Rosana Maria Nascimento de Assunção $0^{2}$ (i) and Daniel Pasquini' ${ }^{*}$ (i) \\ 'Instituto de Química, Universidade Federal de Uberlândia - UFU, Uberlândia, MG, Brasil \\ ${ }^{2}$ Instituto de Ciências Exatas e Naturais do Pontal, Universidade Federal de Uberlândia - UFU, \\ Ituiutaba, MG, Brasil \\ ${ }^{3}$ Departamento de Áreas Acadêmicas, Instituto Federal de Goiás, Itumbiara, GO, Brasil \\ ${ }^{4}$ Instituto de Ciências Exatas, Naturais e Educação, Universidade Federal do Triângulo Mineiro - UFTM, \\ Uberaba, MG, Brasil \\ *danielpasquini2013@gmail.com
}

\begin{abstract}
In the present study, catalytic activity of dense, porous, electrospun membranes of polysulfone (PSF) and polysulfone with sulfonated polystyrene (PSF PSS) have been evaluated in reactions of esterification of oleic acid with methanol, in times that varied from 10 to 480 minutes. Conversion to biodiesel has been confirmed by FTIR and quantified through gas chromatography. The results showed the catalysts used were effective in the esterification reaction studied and the PSF_PSS electrospun membrane has presented the best conversion to methyl oleate, reaching $70.5 \%$ in a 10 -minute reaction and $95.8 \%$ in a 240 -minute reaction, when methanol:oleic acid molar ratio of $10: 1,5 \%$ of catalyst and temperature of $100{ }^{\circ} \mathrm{C}$ were used. Considering the performance of solid catalysts described in literature, mainly related to reaction times and conversion of the process, this study reveals a promising feasibility of using electrospun membranes of PSF_PSS for developing a heterogeneous acid catalyst aimed to biodiesel synthesis.
\end{abstract}

Keywords: biodiesel, esterification, membranes, polysulfone, sulfonated polystyrene.

How to cite: Lima, A. P., Vieira, A. T., Aud, B. N., Batista, A. C. F., Morais, L. C., Faria, A. M., Assunção, R. M. N., \& Pasquini, D. (2021). Esterification of oleic acid employing sulfonated polystyrene and polysulfone membranes as catalysts. Polimeros: Ciência e Tecnologia, 31(3), e2021027. https://doi.org/10.1590/0104-1428.20210067

\section{Introduction}

Increasing population, urbanization and industrialization induce to a drastic need of energy. It is estimated that the global demand for energy will increase from almost 286 million barrels of oil equivalent per day (mboe/d) in 2018 to more than $357 \mathrm{mboe} / \mathrm{d}$ in 2040, with an average increase of around $1 \%$ per year ${ }^{[1]}$. The main energy source to the whole world is fossil biofuels, which includes all conventional sources of energy, such as petroleum-based, methane and coal. Due to the non-renewable nature of these resources, systematic rise in energy import prices and environmental factors, the interest in alternative sources of energy is increasingly growing ${ }^{[2]}$. In this context, biodiesel emerges as a biofuel that has similar properties to diesel fuel and has several benefits, such as being renewable, biodegradable, non-flammable, non-toxic, non-explosive and with low level of sulphur and pollutants emissions ${ }^{[3,4]}$.

Alkyl fatty acid esters, or biodiesel, may be produced by transesterification of triglycerides or by esterification of free fatty acid with short chain alcohols in the presence of a catalyst ${ }^{[5]}$. The transesterification reaction performed with homogeneous alkaline catalysts is the technology commonly applied in biodiesel industry, presenting high yields, moderate operation conditions and fast reaction rates. Nevertheless, when oils with high acidity and moisture are applied with basic catalysts, production effectiveness decreases due to saponification reactions ${ }^{[2,6,7]}$. Although homogeneous acid catalyst is insensitive to free fatty acid content and has the potential to simultaneously perform esterification and transesterification reactions, the process has some disadvantages, such as equipment corrosion, slow reaction rates and great amount of effluents to be treated, increasing environmental pollution and production costs ${ }^{[6,8]}$. Thus, solid acid catalysts are a promising replacement to the process, since they are easily recovered and reused in the reaction, avoid reactor corrosion problems and reduce the stages of product purification ${ }^{[3,4]}$. Recently, fatty acid esterification from long hydrocarbon chain fatty acids in the presence of acid catalysts has drawn great interest, since the esters produced can also be applied as biofuels ${ }^{[9]}$. Comprehensively considering, heterogeneous acid catalysts as sulfated zirconia ${ }^{[10]}$, ion exchange resin ${ }^{[11]}$, materials based on carbon ${ }^{[7]}$, zeolite ${ }^{[12]}$ and heteropoly acids ${ }^{[13]}$ are good 
examples of solid catalysts to this reaction, once they display relatively high catalytic activity in moderate conditions ${ }^{[14]}$. When it comes to esterification reaction mechanisms, the process of biodiesel acquisition occurs with the formation of an oxonium ion through protonation of the fatty acid, thereby increasing the electrophilic character of carbonyl group and facilitating the nucleophilic attack from the alcohol in order to produce a tetrahedral intermediate. Subsequently, this intermediate goes through rearrangement, a water molecule is withdrawn, the ester is formed and the catalyst is recovered ${ }^{[2]}$, as shown in Figure 1.

Functional polymer materials, such as microspheres and membranes, chemically modified with acid groups are also viable options to overcome deficiencies and replace liquid acids in several organic reactions (transesterification and esterification, among them). The most used in heterogeneous acid catalysis are sulfonic resins (cation exchangers), Nafion non-porous resins and Amberlyst macroporous resins being the most common ${ }^{[15]}$. In literature, there are many papers which report the use of acid polymer materials as solid catalysts in reactions aiming biodiesel production ${ }^{[16-21]}$.

Polystyrene (PS), a thermoplastic polymer with good mechanic and insulating properties widely used in beaker production, transparent packing for foods, audio/video packaging, and light bulbs caps, among others ${ }^{[22]}$, may be easily modified through sulfonation reactions to be applied as solid catalyst ${ }^{[18]}$. Meanwhile, a careful control of its degree of sulfonation (DS) is needed, considering some materials with high DS - for being soluble in water - would have little application in heterogeneous catalysis ${ }^{[23]}$. Also belonging to the thermoplastic class, there is polysulfone (PSF), a polymer formed by two monomers, bisphenol-A and diphenyl sulfone, which has great mechanic resistance, good dimensional and thermic stability, adequate flexibility, and high chemical and hydrolytic stability ${ }^{[24,25]}$. This polymer has been broadly used in resin manufacturing are allocated to the construction of

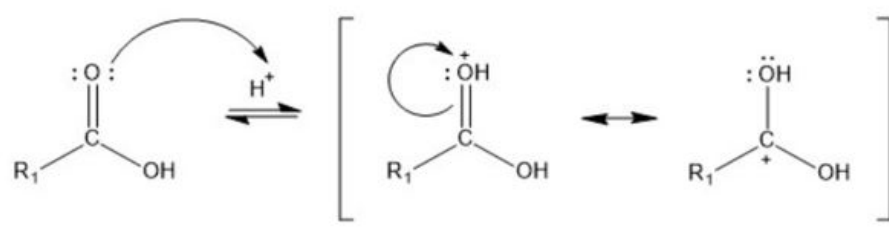

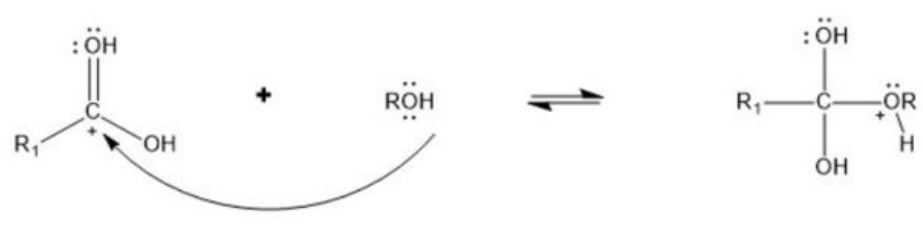

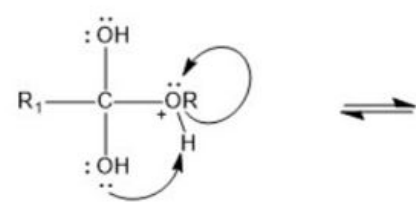<smiles>[R]C(O)(O)O</smiles>

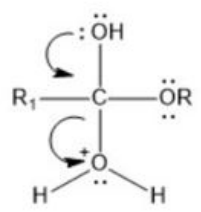<smiles>C=C</smiles><smiles></smiles><smiles>[18OH]</smiles><smiles>[R]C([R7])=[Co]CCOC</smiles><smiles>[R]C(=O)O</smiles>

Figure 1. Esterification mechanism of fatty acids catalyzed by acid. 
parts and equipments in electrical and automotive engineering, household and medical equipments and also as membrane materials for being highly thermostable ${ }^{[26]}$.

Considering this context, the preparation and characterization of dense (D), porous (P) and electrospun (E) membranes of polysulfone and polysulfone with sulfonated polystyrene (PSF_PSS) had been reported in a previous paper generated in our laboratory, aiming a preliminary evaluation of their catalytic properties in esterification reactions from oleic acid with methanol ${ }^{[27]}$. Due to the obtained results that illustrated the good performance of PSF PSS membranes as heterogeneous acid catalysts in the reactional time of two hours, esterification experiments have been expanded in the work reported in the present paper, ranging reaction times, with the aim of improving the maximum obtainable conversion, linking the catalytic activity with physical and chemical properties from different membranes.

\section{Materials and Methods}

\subsection{Materials}

For the esterification reaction, oleic acid (Fluka Analytical) and methanol (PA, Sigma Aldrich) have been used. Dense, porous and electrospun membranes of polysulfone, with maximum degradation temperatures $\left(\mathrm{T}_{\text {max }}\right)$ of 531, 532 and $531{ }^{\circ} \mathrm{C}$, respectively, and dense, porous and electrospun membranes of polysulfone with sulfonated polystyrene, with $\mathrm{T}_{\text {máx }}$ of 526,527 and $527{ }^{\circ} \mathrm{C}$ and superficial area of $\sim 0,5.4$ and $184.4 \mathrm{~m}^{2} \mathrm{~g}^{-1}$, respectively, have been used as catalysts in this reaction. These membranes have been produced and characterized according to the previously mentioned paper ${ }^{[27]}$ using the Carl Zeiss EVO MA10 and Tescam VEGA 3 LMU microscopes, which evidenced the homogeneous structures, materials with pores and materials formed by nanofiber networks. Dense, porous and electrospun membranes, respectively, have been produced as shown in
SEM micrographs in Figure 2. Potassium bromide (PA, Vetec) for infrared analysis and methyl oleate (Sigma Aldrich) for gas chromatography with flame ionization detector have also been used in the development of this paper.

The sulfonation degree (SD) of PSF_PSS membranes was determined by titration with a standardized $\mathrm{NaOH}$ solution $0.01 \mathrm{~mol} \mathrm{~L}^{-1}$. The SD was calculated using Equation 1 .

$$
S D=\frac{\left(104 * M_{\mathrm{NaOH}} * V_{\mathrm{NaOH}}\right)}{m-\left(81 * M_{\mathrm{NaOH}} * V_{\mathrm{NaOH}}\right)}
$$

Where:

$104=$ Molar mass of the monomeric unit $\left(\mathrm{g} \mathrm{mol}^{-1}\right)$.

$\mathrm{M}_{\mathrm{NaOH}}=$ Concentration of the standard $\mathrm{NaOH}$ solution $\left(\mathrm{mol} \mathrm{L}^{-1}\right)$.

$\mathrm{V}_{\mathrm{NaOH}}=$ Volume of $\mathrm{NaOH}$ solution spent in the titration (L). $\mathrm{m}=$ Sample mass $(\mathrm{g})$.

$81=$ Molar mass of the $\mathrm{SO}_{3} \mathrm{H}$ group $\left(\mathrm{g} \mathrm{mol}^{-1}\right)$.

\subsection{Esterification reaction}

The catalytic performance of PSF and PSF_PSS membranes has been evaluated in the previously mentioned paper ${ }^{[27]}$ in esterification reactions from oleic acid with methanol in a two-hour time. In this present paper, catalytic activity from membranes has been evaluated in different reactional times, ranging from 10 to 480 minutes. For this reaction, $5 \%$ of catalyst was added to methanol and the compound was kept resting for 24 hours. Afterwards, this solution was put into a Parr reactor, model 4848, together with oleic acid. The alcohol:oleic acid molar ratio was 10:1 and the reaction occurred at $100{ }^{\circ} \mathrm{C}$. At the end of the process, the catalyst was removed from the reactional mean by simple filtration, and the product was submitted to evaporation under a reduced pressure process in order to withdraw excessive water and methanol.
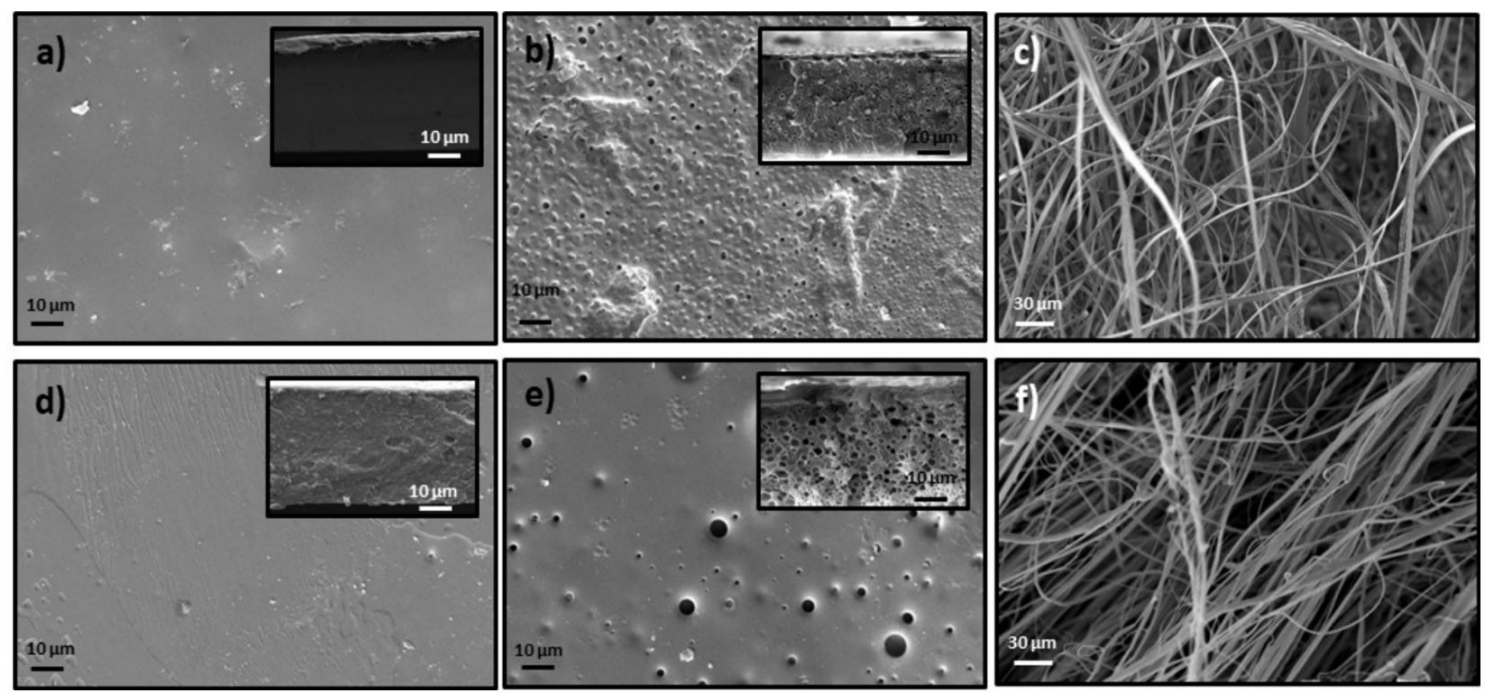

Figure 2. SEM of membranes: (a) PSF Dense (magnification 2,000x); (b) PSF Porous (magnification 2,000x); (c) PSF Electrospun (magnification 250x); (d) PSF_PSS Dense (magnification 2,000x); (e) PSF_PSS Porous (magnification 2,000x); (f) PSF_PSS Electrospun (magnification 250x) ${ }^{[27]}$. The inset shows SEM images of the fractured surface on their respective membranes (magnification 5,000x). 
The catalyst reuse test was performed for the PSF_PSS-E 10 min membrane. The catalysts were separated by simple filtration, washed with $10 \mathrm{~mL}$ anhydrous ethanol and $10 \mathrm{~mL}$ water, followed by a drying at $70^{\circ} \mathrm{C}$ for $3 \mathrm{~h}$.

\subsection{Characterization techniques}

Analyses of characterization performed to the obtained methyl esters included Fourier transform infrared (FTIR) and gas chromatography with flame ionization detector (GC-FID).

FTIR spectra, using a Shimadzu IRPrestige-21 equipment, has been used to identify functional groups in the samples by $\mathrm{KBr}$ method and registered in the range of $4000-400 \mathrm{~cm}^{-1}[28]$.

For quantifying the methyl ester formation, an analytical curve from methyl oleate standard has been elaborated, being the analyses from the standard and the conversion products performed in a Thermo ${ }^{\circledR}$ gas chromatograph, model Focus GC. The temperature of the column oven was kept in isotherm to $190^{\circ} \mathrm{C}$. Other technique elements included: split injection, with flux division $1: 10$ and temperature of $250^{\circ} \mathrm{C}$; flame ionization detection, with temperature detection of $250^{\circ} \mathrm{C}$; injection of $1 \mu \mathrm{L}$ sample; total analysis time for each sample of 5 minutes. Applied column: capillary column of stationary poly (ethylene glycol), Carbowax brand, $30 \mathrm{~m}$ length, $0.32 \mathrm{~mm}$ intern diameter and $0.25 \mu \mathrm{m}$ film thickness.

\section{Results and Discussions}

The polymeric catalyst activity is influenced by the incorporated sulfonic groups providing acidic sites for the esterification. Thus, the PSF_PSS membranes were evaluated for the sulfonation degree and obtained a SD value equal to $24 \%$.
Figures 3 and 4 show spectra from products obtained by esterification using PSF and PSF_PSS membranes, respectively, in all reaction times studied. As the main characteristic changes of oleic acid conversion in biodiesel are focused in the 1800 to $1100 \mathrm{~cm}^{-1}$ region, only this will be presented to make the discussion easier. Analyzing the spectra, it is observed that the band in $1710 \mathrm{~cm}^{-1}$ corresponding to the stretching from $\mathrm{C}=\mathrm{O}$ bond of acids is more pronounced in products that used PSF membranes, proving that there was not oleic acid full consumption in these esterification reactions. Band in $1742 \mathrm{~cm}^{-1}$ assigned to $\mathrm{C}=\mathrm{O}$ bond from esters is more pronounced in products obtained when PSS_PSF membranes have been applied as catalysts, pointing an increase in biodiesel formation. Furthermore, stretching from $\mathrm{O}_{-} \mathrm{CH}_{3}$ bond located in $1196 \mathrm{~cm}^{-1}$, typical of methylic biodiesel, is more evident in product spectra obtained when PSF_PSS membranes catalyzed the reaction, showing greater oleic acid conversion to methyl oleate in these reactional systems ${ }^{[8,29,30]}$.

Biodiesel quantification produced by the esterification reactions has been performed by GC-FID and an analytical curve has been built to determine the concentration of methyl oleate formed. Linear regression proved to fit well to data, with linear regression coefficient of 0.998 , by the internal standard method. Biodiesel conversion values obtained in catalyzed reactions by dense, porous and electrospun membranes of PSF and PSF_PSS, after the reaction times of $10,30,60,90,120,240,360$ and 480 minutes are listed in Table 1.

Analyzing Table 1, it is observed that, in general, PSF membranes have presented low oleic acid conversion into methyl oleate, showing average results only in long reactional times, while PSF_PSS membranes have presented better results in all periods of time studied, reaching even satisfying (a)

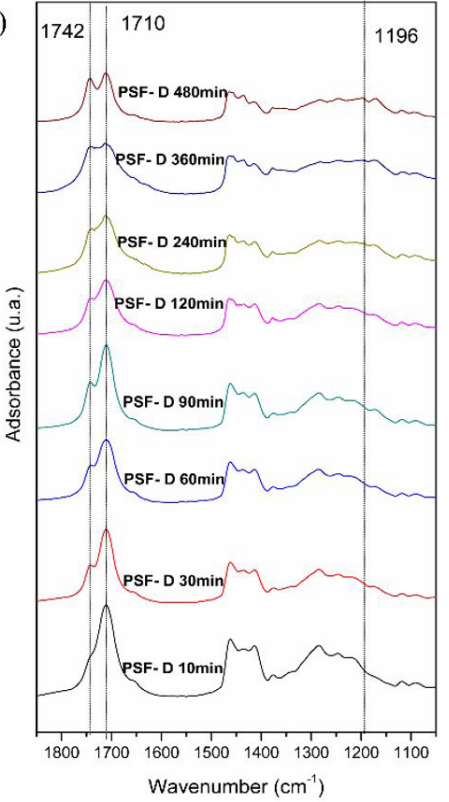

(b)

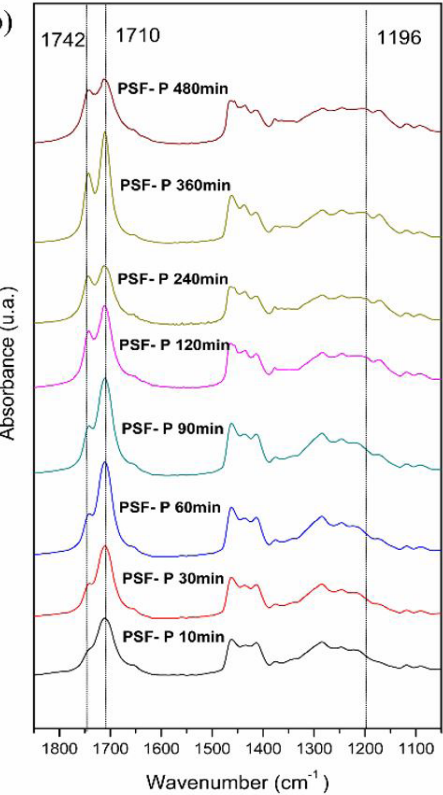

(c)

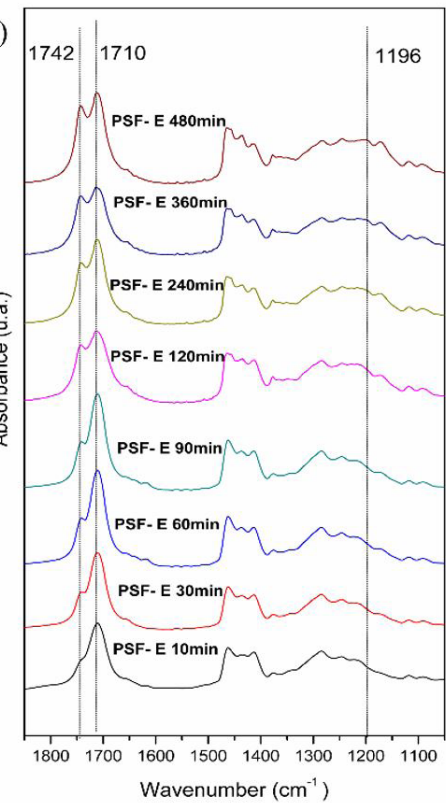

Figure 3. FTIR of membranes of PSF at all reaction times: (a) dense, (b) porous and (c) electrospun. 

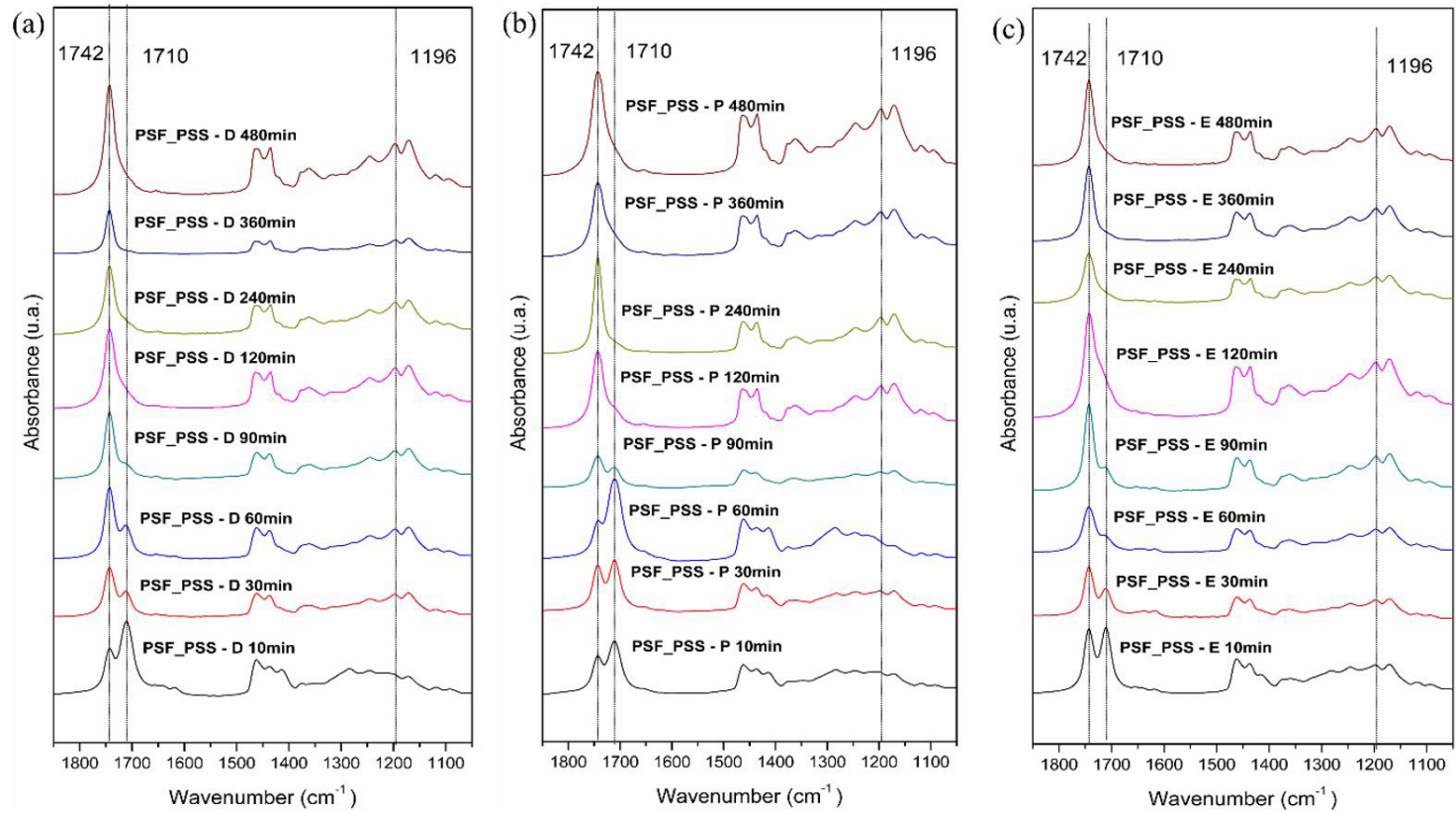

Figure 4. FTIR of membranes of PSF_PSS at all reaction times: (a) dense, (b) porous and (c) electrospun.

conversions in reaction times relatively low. PSF electrospun membrane provided a conversion of $7.5 \%$ in 10 minutes, whereas PSF PSS electrospun membrane converted $70.5 \%$ of fatty acid to methylic ester in the same time range. Comparing the performance of porous membranes in 60 minutes of reaction, it is observed that the PSF membrane resulted in a conversion of $18.0 \%$, whereas PSF_PSS membrane led to a conversion of $65.5 \%$. As an example of dense membranes, a conversion of $15.7 \%$ was obtained for the PSF membrane, whereas the catalyzed reaction with PSF PSS converted $63.9 \%$ in 90 minutes of reaction. These results showed that the presence of sulfonated polystyrene in membranes has increased the conversion efficiency, as more active acid sites were available to catalyze the reaction.

The best conversion rates found for a PSS PSF electrospun membrane, even in short reaction times, may be attributed to its large superficial area, which allows reagents (methanol and oleic acid) to effectively spread in the catalytically active sites, increasing interaction due to better accessibility ${ }^{[5,11,20]}$. The superficial area of this membrane, for example, is approximately 34 times larger than the one from PSF_PSS porous membrane, whereas dense membrane has a superficial area near zero.

In some cases, reaction conversion rates decreased while reaction time increased. For instance, the catalyzed esterification with PSF_PSS electrospun membrane, has converted $81.4 \%$ in a 360 -minute reaction, while in 480 minutes this value has dropped to $68.1 \%$. This may be attributed to the reversibility of esterification reactions, indicating that prolonged times may cause hydrolysis of the formed ester ${ }^{[7,8]}$.

A pattern of similar results had been reported in the authors' previously mentioned paper, which has evaluated the catalytic performance of these membranes in two reaction times as a function of oleic acid consumption. The values of fatty acid concentration found have shown that PSF membranes were not effective to catalyze the reaction, and better results were obtained when PSS_PSF porous and electrospun membranes were used as catalysts ${ }^{[27]}$.

The use of polymer acids catalysts in esterification reactions is already the subject of study in literature. In the paper of Grossi et al. ${ }^{[18]}$, oleic acid esterification has been performed using sulfonated polystyrene and a conversion of approximately $90 \%$ was found in 8 hours of reaction. Gomes et al. ${ }^{[20]}$ have studied esterification of several fatty acids catalyzed by porous co-polymer polydivinylbenzene-co-triallylamine and it was found for the oleic acid methanolysis a yield of $92 \%$ after 10 hours of reaction. Dechakhumwat et al. ${ }^{[5]}$ studied the catalytic activity from a sulfonated residue derived from corn on the cob in oleic acid esterification with methanol, and they obtained a methyl oleate yield next to $80 \%$ after 8 hours of reaction. Pan et al. ${ }^{[21]}$ have carried out esterification reactions using an acid catalyst obtained by sulfonation of ethylenediamine in polydivinylbenzene, and after a 4 -hour reaction at $100{ }^{\circ} \mathrm{C}$ they obtained $85 \%$ conversion. Considering the conversion results obtained in the present study, one can affirm that though heterogeneous catalysis usually requires more severe reactional conditions and longer periods of time to obtain a good performance, 10 minutes of reaction were enough to obtain a significant conversion when PSF_PSS electrospun membrane was applied as reaction catalyst.

The catalyst reuse test was performed for the reaction condition: molar ratio oleic acid:methanol 1:10, temperature of $100{ }^{\circ} \mathrm{C}, 5 \%$ catalyst and 10 minutes of reaction for the electrospun membrane (PSF_PSS-E $10 \mathrm{~min}$ ). Figure 5 show FTIR from products obtained by esterification in three reuse cycles. 
Table 1. Percentage conversion of oleic acid to methyl oleate, measured by GC-FID.

\begin{tabular}{|c|c|}
\hline Sample & Conversion (\%) \\
\hline PSF-D $10 \mathrm{~min}$ & 10.4 \\
\hline PSF-D $30 \mathrm{~min}$ & 7.8 \\
\hline PSF-D $60 \mathrm{~min}$ & 8.3 \\
\hline PSF-D $90 \mathrm{~min}$ & 15.7 \\
\hline PSF-D $120 \mathrm{~min}$ & 12.2 \\
\hline PSF-D $240 \mathrm{~min}$ & 21.2 \\
\hline PSF-D $360 \mathrm{~min}$ & 54.7 \\
\hline PSF-D $480 \mathrm{~min}$ & 42.4 \\
\hline PSF-P 10 min & 6.6 \\
\hline PSF-P $30 \mathrm{~min}$ & 12.7 \\
\hline PSF-P $60 \mathrm{~min}$ & 18.0 \\
\hline PSF-P 90 min & 22.3 \\
\hline PSF-P 120 min & 19.3 \\
\hline PSF-P $240 \mathrm{~min}$ & 31.3 \\
\hline PSF-P $360 \mathrm{~min}$ & 52.1 \\
\hline PSF-P $480 \mathrm{~min}$ & 59.6 \\
\hline PSF-E 10 min & 7.5 \\
\hline PSF-E $30 \mathrm{~min}$ & 11.2 \\
\hline PSF-E $60 \mathrm{~min}$ & 11.3 \\
\hline PSF-E 90 min & 14.4 \\
\hline PSF-E $120 \mathrm{~min}$ & 16.6 \\
\hline PSF-E $240 \mathrm{~min}$ & 26.4 \\
\hline PSF-E $360 \mathrm{~min}$ & 51.2 \\
\hline PSF-E $480 \mathrm{~min}$ & 39.9 \\
\hline PSF_PSS-D $10 \mathrm{~min}$ & 30.0 \\
\hline PSF_PSS-D $30 \mathrm{~min}$ & 56.2 \\
\hline PSF_PSS-D $60 \mathrm{~min}$ & 87.0 \\
\hline PSF_PSS-D $90 \mathrm{~min}$ & 63.9 \\
\hline PSF_PSS-D $120 \mathrm{~min}$ & 91.6 \\
\hline PSF_PSS-D $240 \mathrm{~min}$ & 85.1 \\
\hline PSF_PSS-D $360 \mathrm{~min}$ & 72.5 \\
\hline PSF_PSS-D $480 \mathrm{~min}$ & 95.4 \\
\hline PSF_PSS-P $10 \mathrm{~min}$ & 38.9 \\
\hline PSF_PSS-P $30 \mathrm{~min}$ & 40.0 \\
\hline PSF_PSS-P $60 \mathrm{~min}$ & 65.5 \\
\hline PSF_PSS-P $90 \mathrm{~min}$ & 56.3 \\
\hline PSF_PSS-P $120 \mathrm{~min}$ & 73.4 \\
\hline PSF_PSS-P $240 \mathrm{~min}$ & 62.8 \\
\hline PSF_PSS-P $360 \mathrm{~min}$ & 63.3 \\
\hline PSF_PSS-P $480 \mathrm{~min}$ & 70.7 \\
\hline PSF_PSS-E $10 \mathrm{~min}$ & 70.5 \\
\hline PSF_PSS-E $30 \mathrm{~min}$ & 63.4 \\
\hline PSF_PSS-E $60 \mathrm{~min}$ & 70.6 \\
\hline PSF_PSS-E $90 \mathrm{~min}$ & 69.0 \\
\hline PSF_PSS-120 min & 59.1 \\
\hline PSF_PSS-E $240 \mathrm{~min}$ & 95.8 \\
\hline PSF_PSS-E $360 \mathrm{~min}$ & 81.4 \\
\hline PSF_PSS-E $480 \mathrm{~min}$ & 68.1 \\
\hline
\end{tabular}

Analyzing the FTIR spectra in Figure 5, it is observed that the band in $1710 \mathrm{~cm}^{-1}$ corresponding to the stretching from $\mathrm{C}=\mathrm{O}$ bond of acids gradually increases and is more pronounced on the third reuse, proving that there was not oleic acid full consumption in these esterification reactions. The band in $1742 \mathrm{~cm}^{-1}$ assigned to $\mathrm{C}=\mathrm{O}$ bond from esters is more pronounced in product obtained in first reuse and gradually decreases. The loss of catalyst activity may

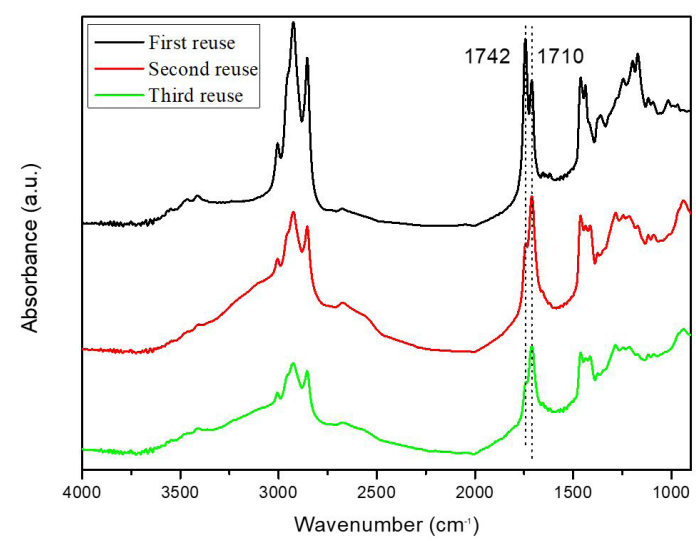

Figure 5. FTIR from products obtained by esterification using PSF_PSS electrospun membranes in three reuse cycles.

be due to a reduced surface area and reduced acid site concentration $^{[19]}$. In the first reuse, the catalyst showed a higher catalytic activity and this leads to the conclusion that this catalyst presents possibilities for reuse.

\section{Conclusions}

In this paper, catalytic activity from six polymer membranes of PSF and PSF_PSS were investigated in esterification of oleic acids with methanol, in different reactional times. FTIR has confirmed the formation of methylic esters and the consumption of oleic acid. And by using gas chromatography, it was possible to quantify methyl oleate formation as a reaction product. The results have shown that PSF_PSS membranes, having more acidic sites in their structure due to the presence of sulfonated polystyrene, had a better catalytic performance than PSF membranes. Having a larger superficial area, the electrospun membrane resulted in a conversion of $70.6 \%$ with only 10 minutes of reaction and $95.8 \%$ in 240 minutes. Thus, results have shown that polysulfone with sulfonated polystyrene membranes, in particular electrospun, may be successfully applied as heterogeneous catalyst acids in esterification reactions from oleic acid with methanol, aiming biodiesel production, mainly due to the good conversion achieved in short reaction times with the possibility of reusing the catalyst.

\section{Acknowledgments}

The authors wish to thank the Coordination for the Improvement of Higher Education Personnel - Graduate Support Program (CAPES/PROAP), Brazilian National Council for Scientific and Technological Development (CNPq), Brazilian Study and Project Funding Agency (FINEP), Federal Institute of Goiás (IFG) and Minas Gerais Research Foundation (FAPEMIG).

\section{References}

1. Organization of the Petroleum Exporting Countries. (2019). World Oil Outlook 2040. Austria: OPEC Secretariat. Retrieved in 2021, August 31, from https://www.opec.org/opec_web/ 
static_files_project/media/downloads/publications/WOO_2019. pdf

2. Ambat, I., Srivastava, V., \& Sillanpää, M. (2018). Recent advancement in biodiesel production methodologies using various feedstock: a review. Renewable \& Sustainable Energy Reviews, 90, 356-369. http://dx.doi.org/10.1016/j.rser.2018.03.069.

3. Chua, S. Y., Periasamy, L. A. P., Goh, C. M. H., Tan, Y. H., Mubarak, N. M., Kansedo, J., Khalid, M., Walvekar, R., \& Abdullah, E. C. (2020). Biodiesel synthesis using natural solid catalyst derived from biomass waste - A review. Journal of Industrial and Engineering Chemistry, 81, 41-60. http://dx.doi. org/10.1016/j.jiec.2019.09.022.

4. Balajii, M., \& Niju, S. (2019). Biochar-derived heterogeneous catalysts for biodiesel production. Environmental Chemistry Letters, 17(4), 1447-1469. http://dx.doi.org/10.1007/s10311019-00885-x.

5. Dechakhumwat, S., Hongmanorom, P., Thunyaratchatanon, C., Smith, S. M., Boonyuen, S., \& Luengnaruemitchai, A. (2020). Catalytic activity of heterogeneous acid catalysts derived from corncob in the esterification of oleic acid with methanol. Renewable Energy, 148, 897-906. http://dx.doi. org/10.1016/j.renene.2019.10.174.

6. Clohessy, J., \& Kwapinski, W. (2020). Carbon-based catalysts for biodiesel production: A review. Applied Sciences (Basel, Switzerland), 10(3), 918. http://dx.doi.org/10.3390/app10030918.

7. Corrêa, A. P. L., Bastos, R. R. C., Rocha, G. N., Fo., Zamian, J. R., \& Conceição, L. R. V. (2020). Preparation of sulfonated carbon-based catalysts from murumuru kernel shell and their performance in the esterification reaction. RSC Advances, 10(34), 20245-20256. http://dx.doi.org/10.1039/D0RA03217D.

8. Liu, F., Ma, X., Li, H., Wang, Y., Cui, P., Guo, M., Yaxin, H., Lu, W., Zhou, S., \& Yu, M. (2020). Dilute sulfonic acid post functionalized metal organic framework as a heterogeneous acid catalyst for esterification to produce biodiesel. Fuel, 266, 117149. http://dx.doi.org/10.1016/j.fuel.2020.117149.

9. Aguiar, V. M., Souza, A. L. F., Galdino, F. S., Silva, M. M. C., Teixeira, V. G., \& Lachter, E. R. (2017). Sulfonated poly (divinylbenzene) and poly (styrene-divinylbenzene) as catalysts for esterification of fatty acids. Renewable Energy, 114(Pt B), 725-732. http://dx.doi.org/10.1016/j.renene.2017.07.084

10. Booramurthy, V. K., Kasimani, R., Pandian, S., \& Ragunathan, B. (2020). Nano-sulfated zirconia catalyzed biodiesel production from tannery waste sheep fat. Environmental Science and Pollution Research International, 27(17), 20598-20605. http:// dx.doi.org/10.1007/s11356-020-07984-1. PMid:32036538.

11. Pasa, T. L. B., Souza, G. K., Diório, A., Arroyo, P. A., \& Pereira, N. C. (2020). Assessment of commercial acidic ion-exchange resin for ethyl esters synthesis from Acrocomia aculeata (Macaúba) crude oil. Renewable Energy, 146, 469-476. http:// dx.doi.org/10.1016/j.renene.2019.06.025.

12. Al-Ani, A., Mordvinova, N. E., Lebedev, O. I., Khodakov, A. Y., \& Zholobenko, V. (2020). Ion-exchanged zeolite P as a nanostructured catalyst for biodiesel production. Energy Reports, 5, 357-363. http://dx.doi.org/10.1016/j.egyr.2019.03.003.

13. Manikandan, K., \& Cheralathan, K. K. (2017). Heteropoly acid supported on silicalite-1 possesing intracrystalline nanovoids prepared using biomass-an efficient and recyclable catalyst for esterification of levulinic acid. Applied Catalysis A, General, 547, 237-247. http://dx.doi.org/10.1016/j.apcata.2017.09.007.

14. Wang, Y.-T., Fang, Z., \& Zhang, F. (2019). Esterification of oleic acid to biodiesel catalyzed by a highly acidic carbonaceous catalyst. Catalysis Today, 319, 172-181. http:// dx.doi.org/10.1016/j.cattod.2018.06.041.

15. Sani, Y. M., Daud, W. M. A. W., \& Abdul Aziz, A. R. (2014). Activity of solid acid catalysts for biodiesel production: a critical review. Applied Catalysis A, General, 470, 140-161. http://dx.doi.org/10.1016/j.apcata.2013.10.052.

16. Soldi, R. A., Oliveira, A. R. S., Ramos, L. P., \& César-Oliveira, M. A. F. (2009). Soybean oil and beef tallow alcoholysis by acid heterogeneous catalysis. Applied Catalysis A, General, 361(1-2), 42-48. http://dx.doi.org/10.1016/j.apcata.2009.03.030.

17. Caetano, C. S., Guerreiro, L., Fonseca, I. M., Ramos, A. M., Vital, J., \& Castanheiro, J. E. (2009). Esterification of fatty acids to biodiesel over polymers with sulfonic acid groups. Applied Catalysis A, General, 359(1-2), 41-46. http://dx.doi. org/10.1016/j.apcata.2009.02.028.

18. Grossi, C. V., Jardim, E. O., Araújo, M. H., Lago, R. M., \& Silva, M. J. (2010). Sulfonated polystyrene: a catalyst with acid and superabsorbent properties for the esterification of fatty acids. Fuel, 89(1), 257-259. http://dx.doi.org/10.1016/j. fuel.2009.05.029.

19. Andrijanto, E., Dawson, E. A., \& Brown, D. R. (2012). Hypercrosslinked polystyrene sulphonic acid catalysts for the esterification of free fatty acids in biodiesel synthesis. Applied Catalysis B: Environmental, 115-116, 261-268. http://dx.doi. org/10.1016/j.apcatb.2011.12.040.

20. Gomes, R., Bhanja, P., \& Bhaumik, A. (2016). Sulfonated porous organic polymer as a highly efficient catalyst for the synthesis of biodiesel at room temperature. Journal of Molecular Catalysis A Chemical, 411, 110-116. http://dx.doi. org/10.1016/j.molcata.2015.10.016.

21. Pan, H., Liu, X., Zhang, H., Yang, K., Huang, S., \& Yang, S. (2017). Multi-SO3H functionalized mesoporous polymeric acid catalystor biodiesel production and fructose-to biodiesel additive conversion. Renewable Energy, 107, 245-252. http:// dx.doi.org/10.1016/j.renene.2017.02.009.

22. Megahed, A. A., Zoalfakar, S. H., Hassan, A. E. A., \& Ali, A. A. (2018). A novel polystyrene/epoxy ultra-fine hybrid fabric by electrospinning. Polymers for Advanced Technologies, 29(1), 517-527. http://dx.doi.org/10.1002/pat.4159.

23. Martins, C. R., Ruggeri, G., \& De Paoli, M.-A. (2003). Synthesis in pilot plant scale and physical properties of sulfonated polystyrene. Journal of the Brazilian Chemical Society, 14(5), 797-802. http://dx.doi.org/10.1590/S0103-50532003000500015.

24. Saljoughi, E., Mousavi, S. M., \& Hosseini, A. S. (2013). Polysulfone/Brij-58 blend nanofiltration membranes: preparation, morphology and performance. Polymers for Advanced Technologies, 24(4), 383-390. http://dx.doi.org/10.1002/ pat.3092.

25. Mahmoudian, M., Kochameshki, M. G., Mahdavi, H., Vahabi, H., \& Enayati, M. (2018). Investigation of structure-performance properties of a special type of polysulfone blended membranes. Polymers for Advanced Technologies, 29(10), 2690-2700. http://dx.doi.org/10.1002/pat.4395.

26. Venugopal, K., \& Dharmalingam, S. (2012). Desalination efficiency of a novel bipolar membrane based on functionalized polysulfone. Desalination, 296,37-45. http://dx.doi.org/10.1016/j. desal.2012.04.006.

27. Lima, A. P., Tirone, A. V., Batista, A. C. F., Morais, L. C., Souza, P. P., Duarte, M. V. F., \& Pasquini, D. (2018). Produção, caracterização e utilização de membranas de poliestireno sulfonado e polissulfona como catalisadores na reação de esterificação do ácido oleico. Revista Virtual de Química, 10(1), 124-141. http://dx.doi.org/10.21577/1984-6835.20180012.

28. Wang, H.-H., Liu, L.-J., \& Gong, S.-W. (2017). Esterification of oleic acid to biodiesel over a 12-phosphotungstic acid-based solid catalyst. Journal of Fuel Chemistry and Technology, 45(3), 303-310. http://dx.doi.org/10.1016/S1872-5813(17)30018-X.

29. Rabelo, S. N., Ferraz, V. P., Oliveira, L. S., \& Franca, A. S. (2015). FTIR analysis for quantification of fatty acid 
methyl esters in biodiesel produced by microwave-assisted transesterification. International Journal of Environmental Sciences and Development, 6(12), 964-969. http://dx.doi. org/10.7763/IJESD.2015.V6.730.

30. Ruschel, C. F. C., Huang, C. T., Samios, D., \& Ferrao, M. F. (2014). Exploratory analysis applied to attenuated total reflectance fourier transform infrared (ATR-FTIR) of biodiesel/ diesel blends. Quimica Nova, 37(5), 810-815. http://dx.doi. org/10.5935/0100-4042.20140130.

Received: Aug. 31, 2021

Revised: Sept. 25, 2021

Accepted: Oct. 19, 2021 